\title{
0 acolhimento dos refugiados na União Europeia em virtude da securitização da migração na região
}

\section{The Refugees' reception in the European Union due to the securitization of migration in the region}

\section{La acogida de refugiados en la Unión Europea debido a la securitización de la migración en la región}

\author{
Ana Beatriz da Costa Mangueira ${ }^{1}$ \\ Andrea Maria Calazans Pacheco Pacifico ${ }^{2}$ \\ Fábio Rodrigo Ferreira Nobre ${ }^{3}$ \\ Filipe Reis Melo ${ }^{4}$
}

DOI: 10.5752/P.2317-773X.2019v7.n3.p63

Recebido em: 27 de agosto de 2018

Aceito em: 20 de março de 2019

\begin{abstract}
Resumo
Este artigo analisa o acolhimento dos refugiados na União Europeia, considerando a securitização da migração como um empecilho para a proteção dos refugiados acolhidos. Em primeiro, examina-se a discussão política sobre as migrações forçadas na União Europeia, focando nos refugiados, particularmente, no exemplo da Itália, e, em segundo, avalia-se a importância da integração institucional e humanitária dos refugiados no local de acolhimento. Em terceiro, identificam-se soluções para melhorar seu acolhimento nos países da União Europeia. Observou-se, ao final, que os Estados se eximem da sua responsabilidade enquanto importantes atores para a proteção desses migrantes forçados, sendo necessário discutir medidas que contribuam para uma maior cooperação dos Estados, em vez de reforçar a securitização da migração local.
\end{abstract}

Palavras-chave: Acolhimento dos refugiados; União Europeia; Securitização da migração.

\footnotetext{
Abstract

This article reflects on the refugees' reception in the European Union, considering the securitization of migration as a barrier to the protection of hosted refugees. At first, the political discussion on forced migration in the European Union is examined, focusing on refugees and, particularly, in the example of Italy, and, secondly, the importance of institutional and humanitarian integration of refugees in the host country is evaluated. Thirdly, solutions to improve their protection in the European Union countries are identified. Lastly, it was observed that States exempt themselves from their responsibilities with regards to being important actors to the protection of these forced migrants, being necessary to discuss measures that foster cooperation among states, instead of reinforce the securitization of local migration.
}

1. Mestranda em Relações Internacionais pelo Programa de Pós-Graduação em Relações Internacionais da Universidade Estadual da Paraíba (PPGRI/UEPB) João Pessoa/Brasil. ORCID: 0000-00023246-0058 (1D)

2. Pós-doutora em Direito Internacional dos Refugiados pela Universidade de York, Canadá. Professora adjunta da graduação e do mestrado, do Curso de Relações Internacionais da Universidade Estadual da Paraíba, e coordenadora do Núcleo de Estudo e Pesquisa sobre Deslocados Ambientais (Nepda). João Pessoa/Brasil. ORCID: 0000-0002-27447166 (iD)

3. Fábio Rodrigo Ferreira Nobre é, atualmente, professor do Programa de Pós-Graduação em Relações Internacionais e da graduação em Relações Internacionais da Universidade Estadual da Paraíba (UEPB). Doutor (2016) e mestre (2013) em Ciência Política pela Universidade Federal de Pernambuco (UFPE). João Pessoa/Brasil. ORCID: 0000-0002-2905-0541 (D)

4. Professor da graduação e do programa de pós-graduação em Relações Internacionais da Universidade Estadual da Paraíba (UEPB). Doutor em Ciência Política pela Universidad de Deusto (Espanha) e Pós-Graduação em Estudos Europeus pela mesma Universidade. João Pessoa/Brasil. ORCID: 0000-00019472-6491 (iD)

Keywords: Refugees' reception; European Union; Securitization of migration. 


\section{RESUMEN \\ Este artículo examina la acogida de refugiados en la Unión Europea, conside- rando la securitización de la migración como un obstáculo para la protección de los refugiados acogidos. En primer lugar, se examina el debate político sobre las migraciones forzadas en la Unión Europea, centrándose en los refugiados y, en particular, en el ejemplo de Italia, y, en segundo lugar, la importancia de la integración institucional y humanitaria de los refugiados en el sitio de acogida. En tercer lugar, se identifican soluciones para mejorar su acogida en los países de la Unión Europea. Al final, se observó que los Estados se afastan de su responsa- bilidad como actores importantes para la protección de estos migrantes forzados, siendo necesario el debate de las medidas que contribuyan a una mayor coopera- ción entre los Estados, en lugar de reforzar la securitización de la migración local. \\ Palabras-clave: acogida de refugiados; Unión Europea; Securitización de la migración}

Em grande parte da trajetória dos estudos de Relações Internacionais, os migrantes forçados foram negligenciados enquanto objeto de abordagem. Discutir os contextos históricos que provocaram e ainda provocam as migrações forçadas, como os conflitos e as guerras, tendia a ser a forma mais comum de tratar o tema em questão. No entanto, quando, na década de 1950, foi criado um regime de proteção para os refugiados, após a crise de migração forçada causada pela Segunda Guerra Mundial (BARNETT, 2002), esses indivíduos passaram a adquirir uma posição mais importante como objeto de análise. Ainda que no contexto pós-Segunda Guerra Mundial a questão dos refugiados tenha adquirido maior importância para o Direito Internacional, entende-se que somente muito tempo depois essa temática obteve relevância no campo de Relações Internacionais. Isso se justifica pelo fato dessa disciplina, no contexto do pós-Guerra, ter voltado sua atenção mais para as causas e para os impactos desse conflito (SMITH, 2013), do que para os indivíduos.

De acordo com Betts (2009), expandir as discussões na política internacional sobre um regime de proteção aos refugiados foi de suma importância tanto para a teoria quanto para a prática. Com isso, entende-se que, de forma imprescindível, o olhar acadêmico, bem como o da sociedade civil, se direcione cada vez mais para os refugiados, a fim de melhor contribuir com a formulação de políticas para sua proteção e de solução dos problemas relacionados a eles.

Com a criação do regime internacional para a proteção dos refugiados, estabelecido por meio de acordo entre Estados, foi determinado que a dignidade humana e os direitos básicos desses indivíduos fossem assegurados (LOESCHER, 2014). No entanto, observa-se que ainda há uma série de lacunas na proteção dos refugiados na prática, uma delas relacionada à falta de cooperação entre esses Estados. Um exemplo é a forma de atuação de alguns países da União Europeia (UE), como Itália e Reino Unido, em que, em muitos casos, os refugiados são mantidos em centros de detenção, em vez de serem acolhidos, conforme prevê o Sistema Europeu Comum de Asilo (SECA) (UNIÃO EUROPEIA, 2014). Nesses casos, os refugiados chegam a ser considerados criminosos, vistos, assim, como uma ameaça ao Estado (PEREIRA, 2016). 
Ao analisar a forma como a União Europeia lida com a questão dos refugiados, nota-se que é comum os seus países membros enquadrarem essa questão em uma agenda de segurança. Isso se fortalece por meio do discurso, constantemente disseminado na Europa, de que a questão dos refugiados é um grande problema nesse continente pelo fato de a Europa fazer fronteira com a África e o Oriente Médio (PAOLETTI, 2014). Contudo, a Europa não é o principal destino dos refugiados, uma vez que esses buscam refúgio principalmente em países vizinhos, ou seja, do mesmo continente dos seus países de origem. Dessa forma, parece tornar-se desnecessária a "situação de emergência" nos países europeus sobre essa questão (PAOLETTI, 2014). Interpreta-se, desse modo, que há um desinteresse dos Estados da UE na proteção dos refugiados e um interesse em securitizar a migração. Sendo assim, questiona-se de que forma são acolhidos os refugiados na União Europeia, levando em consideração a securitização da migração nessa região.

Para nortear a discussão a respeito do tema, as questões relacionadas ao principal objetivo do artigo buscam observar a discussão política sobre as migrações forçadas na União Europeia, tendo como foco os refugiados e utilizando-se do exemplo da Itália, além de discutir a integração institucional e humanitária dos refugiados no local de acolhimento e, por fim, identificar soluções a fim de melhorar o acolhimento dos refugiados nos países da União Europeia.

Dessa forma, o artigo, primeiramente, faz uma breve análise das migrações forçadas internacionais, debruçando-se mais especificamente sobre os refugiados e sobre a discussão política na União Europeia, ressaltando o caso da Itália, em torno da temática. Aqui, chama-se a atenção de como as imigrações extracomunitárias desse bloco têm sido tratadas como uma agenda de segurança (GARCIA, 2014), em que os migrantes representam a ameaça em potencial. Esse processo é conhecido como "securitização da migração", pois, a priori, as imigrações eram parte apenas da esfera política, mas ao ser elevado o seu grau de importância, passam a ser vistas com caráter emergencial (BUZAN; WÆVER; WILDE, 1998), discussão essa aprofundada na segunda parte do artigo. Securitizar a migração torna a situação dos refugiados ainda mais delicada porque afeta $\mathrm{O}$ acolhimento e a proteção desses indivíduos (GARCIA, 2014). Esse processo já é utilizado na União Europeia de forma comum, utilizando-se o argumento de que as migrações, sendo uma ameaça aos Estados, provocariam riscos em vários níveis, dentre eles: o econômico, o social e, além disso, a insegurança relacionada a possíveis atuações terroristas desses imigrantes.

Por fim, o artigo reflete sobre as medidas que podem auxiliar na solução do problema do acolhimento dos refugiados na União Europeia, em virtude da securitização da migração nessa região. Uma das soluções primordiais diz respeito à cooperação dos Estados-membros da UE para esse acolhimento e para proteção dos migrantes forçados que buscam refúgio no Bloco. Logo, o artigo finaliza com algumas considerações a respeito da temática em questão, compreendendo, assim, a relevância de se discutir o acolhimento dos refugiados na União Europeia, e considerando, ainda, a importância de os Estados cooperarem para uma melhor proteção desses migrantes, ao invés de reforçar a securitização da migração. 
Uma discussão política sobre as migrações e o sistema de refúgio na União Europeia

As migrações têm gerado intensas discussões no mundo contemporâneo, embora elas não sejam um novo fenômeno mundial, diferenciando-se em contextos, causas e consequências. Foi com o próprio ato de migrar de uma região para outra que os indivíduos contribuíram para que as sociedades passassem por processos de construção e transformação, proporcionando o surgimento de diversas identidades, crenças, línguas, modo de organização de vida etc. (PEREIRA, 2016). De acordo com Castles (2005, p. 15-16), "as migrações podem contribuir para um maior desenvolvimento e para a melhoria das condições econômicas e sociais, [...] mas podem também ajudar a promover a estagnação e a desigualdade" nas sociedades. Para esse autor, os resultados gerados pelas migrações dependem das características que elas possuem, bem como do posicionamento dos governos que lidam com elas. Castles (2005, p. 15-16) ainda afirma que as migrações podem contribuir "para a erosão das fronteiras tradicionais entre línguas, culturas, grupos étnicos e Estados-nação”, e, dessa forma, provocar um tipo de abalo na estrutura do Estado e de sua autonomia enquanto possuidor de identidades e culturas próprias.

No século XXI, as pessoas têm migrado por diversos motivos, seja em busca de uma melhor qualidade de vida, oportunidades de emprego, oportunidades de estudos, seja por migração forçada causada por perseguições, conflitos ou desastres ambientais (ROCHA; MOREIRA, 2010). É necessário ressaltar que as migrações podem diferenciar-se, além de outras classificações, entre: migrações internas, que são aquelas em que o indivíduo se desloca para outro município ou região dentro de seu próprio Estado, e migrações internacionais, em que os indivíduos atravessam as fronteiras internacionais dos Estados (CASTLES, 2005). Nesse artigo, tratar-se-ão das migrações internacionais, mais especificamente de um grupo de migrantes forçados que atravessam as fronteiras entre Estados, chamados de refugiados.

A pessoa refugiada, de acordo com a Convenção de Genebra de 1951 (ACNUR, 1951), em seu artigo $1^{\circ}$, combinado com o Protocolo de Nova Iorque de 1967, é aquela que está fora de seu país de origem ou nacionalidade e não pode ou não quer voltar a valer-se da proteção deste país por perseguição ou temor bem fundado de perseguição em razão de raça, nacionalidade, religião, grupo social ou opinião política. Juridicamente, a definição de refugiado contém sentido mais específico, diferentemente das outras categorias que são parte das migrações forçadas, como os deslocados internos, os quais não possuem uma proteção jurídica internacional como a dos refugiados. Nesse sentido, percebe-se que os refugiados estão em uma categoria "privilegiada" no que diz respeito à proteção jurídica (PACÍFICO, 2010), mas, ainda assim, sofrem na prática com as falhas e as omissões dos Estados que são membros da Convenção de Genebra supracitada.

As lacunas na proteção dos refugiados podem ser expressas de diversas formas. Uma delas diz respeito à falta de cooperação dos Estados para o acolhimento desses indivíduos. Na Europa, por exemplo, geralmente 
utiliza-se o argumento de que os imigrantes, sem exceção de categoria, ameaçam a estabilidade do Estado em seus diversos níveis (econômico, social ou político) (BUZAN; WAVER; WILDE, 1998). Esse discurso pode contribuir para a falta de responsabilidade com a proteção dos indivíduos que solicitam refúgio. Segundo Giuliani (2012), na década de 1990, com o processo de globalização, a Itália se viu em uma situação de emergência. Isso aconteceu devido às mudanças no fenômeno das migrações, que, por sua vez, desencadeou um aumento de $60 \%$ da população estrangeira da Itália ainda nessa mesma década. Nesse contexto, as políticas de restrição aos migrantes, incluindo os refugiados, foram intensificadas, dificultando tanto o acesso quanto a permanência desses indivíduos na Europa.

Nesse cenário de globalização da década de 1990 e, com efeito, do aumento dos fluxos migratórios, os partidos políticos de direita ${ }^{5} \mathrm{em}$ alguns países da União Europeia passaram a incorporar uma retórica que disseminava o medo dos migrantes (GARCIA, 2014). Esses indivíduos começaram a ser vistos como problemas que os Estados enfrentariam, difundindo uma ideologia para a população de suposta ameaça. O caso italiano sobre a temática serve de exemplo, uma vez que, na Itália, evidenciou-se que tanto os discursos proferidos pela mídia, quanto os discursos de políticos se transformaram em medidas tomadas pelo governo a fim de securitizar a imigração local (VELASCO, 2014). Conforme Garcia (2014, pp. 236-237), no caso da Itália,

\footnotetext{
[a] ótica securitária conjugada à retórica do perigo serviu para justificar a adoção de medidas excepcionais que excedem o quadro jurídico regular, colocando a emergência e a segurança nacional em um lugar de destaque na práticas governamentais e estratégias midiáticas bem como na vida do cidadão comum e nas suas relações com os estrangeiros. Se até os anos 1980 a convivência com os estrangeiros era considerada pacífica ou isenta de violência simbólica e material, no espaço de poucos anos essa postura dá lugar à hostilidade e a eventos cotidianos de violência contra os imigrantes.
}

Com a hostilidade contra os migrantes, riscos são gerados aos refugiados. Em certos casos, como em contextos de conflitos e guerras nos seus países de origem, esses indivíduos se sentem obrigados a sair em busca de refúgio e possuem, como algumas das opções de destino, os países da União Europeia (UE). Para Ferreira (2014, pp. 74-75), os países desse Bloco sempre estiveram entre os principais destinos de migrantes voluntários internacionais, contudo, segundo Fargues e Fandrich (2012), os países europeus também sempre receberam de forma significativa os refugiados. Argumenta-se que, por esse motivo, foi criado o Sistema Dublin, qual seja, um regulamento da UE que estabelece os critérios para os Estados-membros adotarem, dentro de sua responsabilidade, sobre os pedidos de refúgio, tal como determinar o Estado-membro responsável pela solicitação de refúgio (KASPAREK, 2016). Na maioria dos casos, esse Estado é o primeiro local aonde os refugiados entram na UE, o que, para os países que são porta de entrada da Europa, é visto como um problema. Isso agrava a situação dos refugiados, já que muitos desses países, como a Itália, utilizam a detenção de migrantes, incluindo refugiados, um dos motivos para que o Sistema Dublin seja considerado falho.

Para Kasparek (2016), o Sistema Dublin tende a limitar o acesso de refugiados, abandonando essas pessoas que precisam da proteção in-
5. De acordo com Wermuth (2014, p. 193), nesse momento "o que se observa é que a migração se transforma em bode expiatório da profunda crise econômica em curso e grande trunfo dos partidos de direita", ou seja, as migrações passam a ser parte dos discursos políticos como um problema que precisa ser solucionado, a fim de impedir que as áreas econômicas e sociais da sociedade europeia se desestruturem por causa dos imigrantes. Alguns exemplos de partidos "de extrema-direita, que nos últimos anos têm usado o combate à imigração como uma de suas principais plataformas eleitorais" são o partido neofacista Força Nova, Falange, na Espanha, e o Partido Nacional Democrata alemão (VELASCO, 2014, p. 133). 
ternacional. Segundo esse autor, esse sistema foi criado para facilitar o acesso ao refúgio. No entanto, ele funciona como um tipo de 'filtro' para que os membros da UE o utilizem durante o pedido de refúgio. A Itália, por exemplo, buscou implementar políticas restritivas aos migrantes, a começar pelas suas fronteiras (GIULIANI, 2012, p. 279).

A restrição ao acolhimento de imigrantes em países-membros da UE inclui todas as categorias, inclusive a dos refugiados. Independentemente de que esses sujeitos necessitem de acolhimento, os Estados reivindicam o fechamento de fronteiras que, por sua vez, justifica-se por uma política de segurança nacional (SARAIVA, 2017), esquecendo-se da segurança dos próprios sujeitos/refugiados. De acordo com Pacífico (2010, p. 40),

[a]s políticas restritivas fronteiriças são tidas como medidas necessárias pelos Estados nortistas ricos para prevenir os migrantes indesejáveis de deixarem seus países. Tais políticas são parte de uma agenda de segurança global mais ampla, em que os excluídos são tratados como fonte de conflito, terrorismo ou instabilidade.

Desse modo, caracterizar os migrantes como possíveis ameaças à sociedade, contribuindo com a percepção de que eles colaboram com o aumento dos índices de criminalidade e de insegurança, torna-se oportuno para que se pratiquem cada vez mais as políticas de contenção em vez de fornecer refúgio aos refugiados. Além dessas restrições e, portanto, do não fornecimento de assistência social aos refugiados, esses são detidos como migrantes ilegais (LOESCHER, 2014), o que torna a sua situação ainda mais delicada.

Em certos países da União Europeia, como Itália, Reino Unido e Grécia, é comum os refugiados serem detidos e deportados. Os migrantes forçados são mantidos em centros de detenção e, posteriormente, deportados pelos mesmos Estados a que esses indivíduos recorrem para solicitar a condição de refugiado (GARCIA, 2014). De acordo com Harrel-Bond e Voutira (2007), os centros da Europa que recebem os refugiados variam entre centros de acolhimento, como na Suécia e na Grécia, instalações fechadas de prisão para refugiados e outros tipos de imigrantes, como no Reino Unido, e atos de reais prisões, a partir das quais os refugiados passam a ser mantidos em celas até serem condenados como criminosos. Em ocasiões em que é inviável expulsar os estrangeiros instantaneamente, eles são levados aos chamados "Centros de Permanência Temporária", onde ficam por determinado tempo até serem expulsos dos países nos quais pretendiam ficar (GARCIA, 2014). Para Garcia (2014, p. 242), é necessário

\footnotetext{
[o]bservar que, embora a nomenclatura oficial destes centros remeta à configuração de espaços de acolhimento temporário, eles funcionam de fato como centros de detenção, nos quais os imigrantes, potenciais refugiados e solicitantes de refúgio são mantidos em confinamento até que seja concretizada sua expulsão \deportação.
}

Além da situação insatisfatória do acolhimento aos refugiados na União Europeia, esses indivíduos são passíveis de uma série de preconceitos e alvos de atos xenofóbicos, o que torna a sua integração à sociedade que lhes dá refúgio muito difícil. Para Lussi (2015), isso pode ser interpretado como uma política de "criminalização da migração" (explanada a posteriori), que expressa que, como ressaltado, o migrante é caracterizado como um sujeito indesejável. De acordo com essa autora, "a ideia 
de que os estrangeiros atentam contra a segurança da população autóctone é facilmente levada a formas de marginalização dos estrangeiros, favorecendo comportamentos xenófobos que os excluem da população que tem direito à segurança pública" (LUSSI, 2015, p. 140). O sistema de acolhimento dos refugiados na Itália, por exemplo, pode ser visto como problemático, uma vez que esses indivíduos são mantidos em centros de detenção e, ainda, enfrentam obstáculos diversos (i.e. jurídicos, sociais e culturais) quando buscam integrar-se na sociedade italiana.

\section{Os centros de acolhimento para migrantes e a recepção de refugiados na Itália}

A securitização da migração na Itália pode ser entendida como o resultado da soma de pelo menos dois elementos: o posicionamento da sociedade italiana e de grupos domésticos sobre as migrações e das práticas de securitização da migração da União Europeia (ALVES, 2015). Atinente ao primeiro elemento, Zincone e Caponio (2006 apud PAOLETTI, 2011) acreditam que o período eleitoral na Itália é um momento oportuno para o aumento de pressões sobre a questão migratória. Nesse contexto, o apoio da população, que se demonstra a favor de obstáculos a entrada de migrantes no país, é significativo (ZICONE; CAPONIO, 2016 apud PAOLETTI, 2011).

De acordo com Gattinara (2017), parte da população italiana teme refugiados, principalmente de nacionalidades específicas, como sírios. Para esse autor, essa população acredita que os refugiados podem influenciar o aumento de ataques terroristas e ainda afetar a economia do país ${ }^{6}$. Com efeito, promovem-se campanhas 'anti-imigrações' e 'anti-refugiados'. Essas mobilizações acontecem de várias maneiras, como confrontações em centros em que permanecem os refugiados e criação de programas para 'conscientização' dos cidadãos sobre os estrangeiros, utilizando-se de narrativas contra a suposta invasão de populações de culturas distintas (GATTINARA, 2017). Essas questões refletem o modo como os refugiados são acolhidos na Itália, pois, conforme supracitado, o posicionamento da população e de grupos domésticos desse país influencia a securitização da migração.

O relatório da Anistia Internacional de 2017/18 denunciou as ações da Itália quanto às migrações. Migrantes que chegavam ao país pelo mar, no ano 2017, eram resgatados por Organizações Não-Governamentais (ONGs), e a resposta italiana, com o apoio da União Europeia, foi impor um código de conduta para limitar esses resgates (AMNESTY INTERNATIONAL, 2018). Essa pode ser considerada uma política de securitização que afeta pessoas que se encontram em situação de refúgio. Além disso, segundo esse relatório, a Itália busca estabelecer e manter acordos com países terceiros em matéria de migração para conter fluxos migratórios considerados irregulares, o que também gera riscos para as vidas de refugiados. Essa medida compactua com a prisão de migrantes, incluindo pessoas em situação de refúgio, o que desrespeita os direitos humanos (AMNESTY INTERNATIONAL, 2018).

O sistema de acolhimento de refugiados na Itália não é uniforme para requerentes de refúgio e demais categorias de migrantes (ASGI, 2019). Ao chegarem ao país, esses indivíduos podem ser levados para os
6. Mais informações sobre o conteúdo das pesquisas que falam sobre essa parcela da população italiana, ver em Gattinara (2017), cuja referência se encontra nas páginas finais do artigo. 
chamados 'Centros de Primeiros Socorros e Acolhimento' (CPSA), onde são feitas as primeiras identificações dos migrantes, que permanecem nesses locais até serem enviados para outros centros; 'Centros Coletivos', como Centros de Alojamentos (CDA-Centro di Accoglienza), 'Centro de Recepção para Solicitantes de Refúgio' (CARA, Centro di Accoglienza Richiedenti Asilo) e 'Centros de Acolhimento Temporário', os quais são implementados pelas prefeituras quando os outros centros não possuem condições de acolher os migrantes (ALVES, 2015).

A recepção de refugiados na Itália acontece também por meio do Sistema de Solicitantes de refúgio e Refugiados (SPRAR - Sistema di Protezione per Richiedenti Asilo e Rifugiati), que consiste em uma rede formada por autoridades locais e por ONGs, financiadas por fundo públicos, e recepciona os refugiados prestando serviço de assistência e integração. No entanto, esses serviços são prestados somente àqueles que já tenham formalizado sua situação enquanto solicitantes de refúgio ou refugiado, principalmente àqueles que já se encontram no território italiano (ASGI, 2019). Sobre os Centros de acolhimento, conforme a ASGI (2019), a lei italiana não especifica um prazo para a permanência dos indivíduos nesses locais, mas supõe que deve durar até que questões relacionadas à identificação dos migrantes sejam resolvidas.

Os chamados 'Centros de acolhimento' na Itália são utilizados, segundo Alves (2015), para manter migrantes considerados irregulares, ainda que dentre estes estejam os que migraram forçosamente. Além disso, acontecem as expulsões coletivas. Embora elas não sejam possíveis de serem concretizadas de imediato (GARCIA, 2014), violam as normas sobre proteção dos refugiados (ALVES, 2015). Esses Centros são considerados por ONGs e agências da Organização das Nações Unidas (ONU) como locais de risco para os refugiados, pois, embora sejam conhecidos como centros de acolhimento, eles funcionam, de fato, como centros de detenção (GARCIA, 2014).

De acordo com o Global Detention Project (2018), não existe transparência na forma como os refugiados são detidos e mantidos nos Centros de detenção na Itália. Para Martino et al (2012, p. 108), os centros podem ser comparados a prisões, tendo em vista que são instalações de antigos prédios de quarteis militares e, ainda, estão sob forte vigilância. Os migrantes ficam alojados em celas e não podem sair sem autorização (GLOBAL DETENTION PROJECT, 2018). A situação humanitária nesses locais faz parte de um amplo debate entre as organizações humanitárias e o próprio ACNUR, tendo em vista que indivíduos muitas vezes em condições de refúgio são detidos, o que descumpre as diretrizes da Convenção de Genebra sobre refugiados (ALVES, 2015, p. 96). Ademais, associações cooperativas e funcionários que gerenciam os centros de detenção na Itália já foram investigados por corrupção e outros danos que colocavam em risco a vida dos migrantes, como a situação precária desses locais (GLOBAL DETENTION PROJECT, 2018).

Em maio de 2017, o Comitê de Direitos Humanos da ONU criticou a detenção prolongada de refugiados e, ainda, a classificação incorreta dos solicitantes de refúgio como migrantes econômicos. Além disso, esse comitê denunciou os procedimentos severos durante o processo de identifi- 
cação desses sujeitos (AMNESTY INTERNATIONAL, 2018). A Itália, por seu turno, se demonstrou passiva, ignorando pedidos de esclarecimentos sobre a detenção de refugiados e sobre sua permanência nos centros de detenção (GLOBAL DETENTION PROJECT, 2018).

A detenção de refugiados na Itália, embora, na maioria das vezes, arbitrária, constitui apenas uma das práticas que fere os direitos desses migrantes forçados. Os refugiados lidam com problemas de integração na sociedade italiana, a começar com o processo de residência, pois muitas vezes as circunstâncias os levam a optar por viver em prédios abandonados (ASGI, 2014), o que consiste em uma falha do Estado em estabelecer políticas eficientes voltadas à integração dos refugiados, já que eles são privados do acesso à moradia no país (ASGI, 2014). Segundo o último relatório da Anistia Internacional (2018), na Itália, práticas de discriminação no acesso à habitação contra refugiados são comuns. Em agosto de 2017, autoridades italianas expulsaram refugiados que já viviam há alguns anos em Roma (AMNESTY INTERNATIONAL, 2018).

Para Gattinara (2017, p. 328), a maioria dos governos europeus, dentre eles a Itália, apoia a adoção de políticas de segurança voltadas para as migrações. Essas políticas desconsideram, muitas vezes, a garantia da proteção de pessoas que se encontram em situação de refúgio. Por isso, entende-se que o sistema de acolhimento dos refugiados na Itália está imerso em uma problemática que envolve diversos atores, como as ONGs e sua atuação, a recepção em centros de acolhimento ou de detenção e o posicionamento da sociedade civil e de autoridades italianas. A problemática consiste em uma falta de aparelhamento preocupado, de fato, com a situação dos refugiados, que em muitas circunstâncias são detidos e mantidos em centros de detenção ou, ainda, não conseguem se integrar na sociedade italiana devido a práticas xenófobas, comumente vista em outros países da União Europeia.

\section{Discussões políticas sobre refugiados na União Europeia}

Segundo Harrel-Bond e Voutira (2007), tanto a mídia quanto os discursos políticos na Europa dificilmente usam o termo "refugiados" para se referirem a esses indivíduos. Em vez disso, os refugiados são denominados "migrantes irregulares" ou apenas "solicitantes de refúgio", o que pode reforçar ainda mais o obstáculo para sua proteção, enquadrando a temática em uma agenda de segurança (HARREL-BOND; VOUTIRA, 2007). Entende-se, portanto, que ao considerar os refugiados como migrantes irregulares, interpretações errôneas podem ser desencadeadas por parte da população civil europeia, de que todos os migrantes se enquadram no mesmo patamar e, assim, não deveriam ser tratados de forma diferenciada.

Geralmente, os debates que abordam o tema "migrações" são intensificados em contextos de campanhas eleitorais nos países que compõem a UE, como aconteceu com o caso do Brexit(sigla em inglês), que diz respeito à decisão do Reino Unido de sair da União Europeia após um referendo popular (IOV; BOGDAN, 2017). A decisão do Brexit foi, em parte, influenciada pela problemática envolvendo esse tema no Reino 
Unido, uma vez que sua sociedade civil se encontrava insatisfeita com as decisões do Bloco relativas à entrada de imigrantes extracomunitários na UE (IOV; BOGDAN, 2017). Isso se explica justamente pelo entendimento de que os estrangeiros são as sementes de futuros problemas nas sociedades de acolhimento. Assim, "a utilização perspicaz de imagens poderosas de desastres iminentes é uma tática política bem estabelecida” (PAOLETTI, 2014, p. 141).

Outra argumentativa política da UE sobre a temática diz respeito à forma exacerbada com que o fluxo de imigrantes e/ou refugiados é tratada na Europa, onde, em certos contextos, o fluxo é apresentado como muito intenso ou "fora dos limites" em direção aos países desse continente (FERREIRA, 2014). Nota-se que isso, também, é um dos discursos que colabora com a securitização da migração local, porque impõe um caráter de emergência à questão dos refugiados em direção aos países da União Europeia, como o que ocorreu no contexto da Primavera Árabe (COSKUN, 2015), ou seja, período em que eclodiram protestos e revoltas em países no Norte da África no início do ano de 2011, os quais geraram migrações forçadas da sua população (JOFFÉ, 2011).

Naquele período (especialmente de 2011 a 2012), foi atribuído ao fluxo migratório um caráter de emergência. Atinente a isso, propagou-se a notícia de que um grande número de refugiados passou a solicitar refúgio na Europa (JOFFÉ, 2011). No entanto, esse número não aumentou de forma tão considerável, como foi divulgado na mídia europeia (VELASCO, 2014). Reforça-se, então, que a questão dos refugiados foi posta na agenda de segurança europeia, dando a esse assunto já polêmico um caráter emergencial.

Uma agenda de segurança europeia: os refugiados como ameaça existencial?

Na União Europeia, é comum o fluxo de refugiados em direção aos países do bloco gerar uma discussão em nível político e social, pois, geralmente, essa temática é associada a uma provável "crise", a qual poderia afetar a estabilidade social e econômica dos Estados (PAOLETTI, 2014). É dessa forma que a culpa do aumento dos problemas econômicos e da criminalidade se atribui a esses migrantes forçados (MARINUCCI, 2014). Além disso, para Wermuth (2014, p. 192), existe outro fator que contribui para a imagem deturpada desses indivíduos, qual seja, a imagem de "inimigo representado pelo terrorista", que gera receio e insegurança na população.

Segundo Velasco (2014), esse sentimento de insegurança foi manifestado por meio do discurso de David Cameron, realizado no ano de 2011 durante a Conferência de Segurança de Munique. Segundo essa autora, o primeiro ministro britânico declarou que as ações do Reino Unido contra o terrorismo não deveriam ser feitas somente fora das fronteiras, mas sim dentro do próprio território nacional. Isso faz parte de um quadro "neorracista" europeu, em que se atribui ao migrante extracomunitário e, principalmente de religião islâmica, a ideia de ameaça, justificada pela sua condição de migrante e islâmico (VELASCO, 2014). 
De acordo com Cunha (2014), o tema "migração" na União Europeia se encontra entre os assuntos mais discutidos na sua agenda política. Porém, desde a década de 1980, essa questão começou a fazer parte da agenda de segurança, construindo a percepção do migrante como ameaça existencial. Ainda, para esse autor, a migração na Europa possui uma "relação direta com as fronteiras e os mecanismos de controle criados pelos Estados e pela União Europeia” (CUNHA, 2014, p. 191), os quais passaram a cooperar progressivamente na restrição da entrada dos que são considerados "imigrantes ilegais" (CUNHA, 2014). Dentre esses imigrantes, a possibilidade de alguns deles necessitarem de acolhimento, como os refugiados, é excluída, retirando, portanto, os seus direitos enquanto migrante forçado solicitante de refúgio (CUNHA, 2014).

Posteriormente, já na década de 1990, países como a Itália já haviam declarado estado de emergência sobre as imigrações no país (GARCIA, 2014). Essa ação aplica formas restritivas para o impedimento da continuidade do "grande fluxo" de migrantes irregulares, incluindo os refugiados, em direção aos territórios italianos. Nos últimos anos, destacando os anos pós-Primavera Árabe, observa-se que a migração tem adquirido gradativamente caráter de segurança em alguns países, como Itália e Grécia, enquadrando o assunto como uma questão de emergência (GARCIA, 2014).

Nos contextos em que as migrações forçadas se intensificam, e quando alguns dos destinos são países europeus, torna-se mais fácil os Estados da União Europeia disseminarem, por meio de discursos e ações, o entendimento de que essas migrações representam uma questão de segurança (BUZAN; WÆVER; WILDE, 1998). Analisar um assunto, que antes era apenas parte da agenda política, como parte de uma agenda de segurança, significa securitizar o assunto. A securitização é caracterizada como a versão mais extrema de politização, pois tornar um assunto público como parte de uma agenda de segurança significa torná-lo uma questão emergencial que necessita de medidas extraordinárias (BUZAN; WÆVER; WILDE, 1998).

A migração no âmbito da União Europeia é um tema que foi lentamente desenvolvido e tragado pela agenda de segurança, também vinculada a dinâmicas sociais, profissionais e políticas mais amplas. Desde os anos 1980, a migração foi cada vez mais objeto de debates políticos sobre a proteção da ordem pública e sobre a preservação da estabilidade interna. Esses debates também representaram a migração como um desafio para o estado de bem-estar social e para a composição cultural da nação. Em outras palavras, discursos e tecnologias de segurança penetraram na europeização da política de migração. Um dos melhores exemplos é a Convenção de 1990, que cria o Acordo de Schengen de 14 de junho de 1985, ligando a imigração e o refúgio ao terrorismo, ao crime transnacional e ao controle das fronteiras (HUYSMANS, 2000).

O desenvolvimento de discursos e políticas de segurança na área da migração é frequentemente apresentado como uma resposta política inevitável aos desafios para a ordem pública e para a estabilidade interna do aumento do número de imigrantes (ilegais) e solicitantes de refúgio. A securitização da migração no contexto dos debates sobre o futuro do 
Estado de bem-estar social também está inserida na luta pela legitimidade política na ordem política do pós-guerra na Europa. Desafios para o welfare state, que começou a ser alvo de debates turbulentos na década de 1970, não podem ser reduzidos a uma questão de recessão econômica ou a um colapso da espiral entre o rápido crescimento econômico e a criação de direitos sociais (HUYSMANS, 2000).

Este universo social da "dimensão externa da segurança interna" é povoado pela grande maioria dos guardas e policiais da fronteira da UE, designados para o controle dos migrantes. Esse movimento cria um contexto que favorece um conjunto específico de disposições, enquanto inibe firmemente outras pessoas (MEZZADRA, NEILSON, 2008). Em toda a Europa, esse desenvolvimento levou ao surgimento de uma máquina de mobilidade forçada, heterogênea e ramificada, na qual muitos migrantes são confrontados com o fato de serem indesejados e com medidas políticas destinadas a dominar e, portanto, "nomadizá-los" por meio de práticas repetidas de expulsão (DE GENOVA, 2017).

A securitização da migração na União Europeia torna a própria segurança dos refugiados fragilizada (VELASCO, 2014), pois esta política gera restrições ao acolhimento. Sendo assim, ao considerar a migração como uma ameaça existencial, os refugiados estão sujeitos a alguns riscos, como àqueles relacionados à sua permanência nos centros de detenção, ou mesmo àqueles que dizem respeito às práticas xenofóbicas contra esses indivíduos, o que dificulta a sua integração local. Como consequência, em certos casos, o migrante opta pela migração ilegal (LONG, 2014). Nessa acepção, a União Europeia corrobora e reifica a securitização da migração por meio de princípios e decisões tomadas em conjunto, como o fortalecimento da militarização nas fronteiras, o aumento de detenções e ações punitivas (GARCIA, 2014).

Seja qual for sua designação, esses migrantes são cada vez mais colocados como objetos de medos e ansiedades securitizados, ora como possuindo uma agência repulsiva - ou seja, fraudes de identidade, furadores de fila, pessoas que minam o consentimento na política etc. - ou uma agência perigosa - ou seja, criminosos, terroristas, agentes de insegurança etc. De toda forma, parece visível que a securitização da migração nos estados ocidentais resultou em uma série de leis e políticas restritivas que levantam importantes questões sobre a relação entre proteção e política (NYERS, 2003).

As políticas de controle sobre a migração se iniciam nas fronteiras europeias (SARAIVA, 2017). Esse tipo de controle é realizado pela Agência de Fronteira e Guarda Costeira Europeia (Frontex- sigla em inglês) (FRONTEX, 2017), criada pela UE com o objetivo de administrar as políticas sobre migração, assunto em comum entre os seus países-membros (IOV e BOGDAN, 2017). A supervisão das fronteiras europeias também é feita pelo Sistema de Informação Schengen, "que visa aumentar a segurança e facilitar a livre circulação no espaço Schengen" (IOV e BOGDAN, 2017, p. 13-14), que corresponde ao local em que é feita a livre circulação de pessoas na União Europeia, criado a partir do acordo Schengen na década de 1980, no qual os países signatários fornecem o direito de livre circulação para os indivíduos (SCHENGEN VISA INFO, 2017). 
Esse sistema foi implementado na década de 1980, período em que a proteção interna europeia adquiriu maior importância, provocando a intensificação do controle das fronteiras externas (PEREIRA, 2016). Cunha (2014) afirma que o supracitado acordo de Schengen possibilitou que internamente as fronteiras europeias fossem abolidas. No entanto, concomitantemente a isso, as fronteiras externas se fortaleceram, tendo em vista a necessidade, por parte dos Estados, de se protegerem da "ameaça externa", que são os migrantes extracomunitários, isto é, os estrangeiros não europeus. Para Voutira e Doná, (2007), isso põe em evidência a preocupação com a segurança estatal, esquecendo-se da segurança dos próprios indivíduos/refugiados, já que eles são considerados uma potencial ameaça.

Com as severas restrições fronteiriças impostas pelos países da União Europeia, Dijck (2006) afirma que a imigração ilegal pode ser mantida e até mesmo reforçada. Além disso, esse autor afirma que não basta somente o migrante não possuir documentos de identificação para sua imigração ser considerada ilegal (DIJCK, 2006). Nesse sentido, compreende-se que a migração, além de securitizada, é criminalizada. De acordo com Lussi (2015, p. 140), a criminalização das migrações pode-se apresentar de diversas maneiras, a saber:

$$
\begin{aligned}
& \text { a. a que a lei estabelece tipificando o crime da irregularidade migratória; b. a que } \\
& \text { os estereótipos preconceituosos favorecem através de um discurso público ou mi- } \\
& \text { diático de que os migrantes praticam mais crimes do que os nacionais; e c. uma } \\
& \text { mais sutil, consequência de políticas restritivas e discriminatórias que, rejeitando } \\
& \text { os migrantes e refugiados, ao mesmo tempo que pode empurrá-los para os } \\
& \text { circuitos do crime, leva os sistemas repressivos a identificar, prender e condenar } \\
& \text { mais facilmente um estrangeiro do que um cidadão nacional pelo mesmo crime } \\
& \text { ou até a aplicar sanções mais fortes, no caso dos migrantes. }
\end{aligned}
$$

Criminalizar a migração irregular, tornando-a ilegal, ao invés de caracterizá-la como uma prática infringente (LUSSI, 2015), sustenta o processo de securitização da migração, em que o entendimento do migrante como uma ameaça se torna um discurso "natural" (DIJCK, 2006). Mais uma vez, essa análise faz refletir sobre a situação dos refugiados, pois esses, em determinados casos, são considerados migrantes ilegais, excluindo-se o fato de que solicitam refúgio. É necessário lembrar que os refugiados perdem tudo antes e durante o trajeto até chegarem ao local de destino, portanto, normalmente, não possuem documentos nem vistos para a entrada nos Estados europeus. É desse modo que esses indivíduos ficam na mesma categoria dos criminosos transnacionais e migrantes ilegais, simplesmente pelo motivo de terem perdido seus documentos (GARCIA, 2014).

Para Pacífico (2010), quando os Estados estabelecem políticas que restringem as migrações forçadas, os refugiados podem não ser reconhecidos como tais e, portanto, correm o risco de perder os seus direitos como pessoas que necessitam da proteção internacional. Por esse motivo, os refugiados são considerados "atores invisíveis", tendo em vista que são excluídos da sociedade que solicitaram refúgio por conta da sua condição de migrante forçado (HARRELL-BOND; VOUTIRA, 2007 , p. 295). Referente a isso, Lussi (2015, p. 141) afirma que a criminalização das migrações 


\begin{abstract}
[d]eteriora as condições de vida dos migrantes e suas famílias, aumentando processos de exclusão nas sociedades de chegada, o que impede sua integração e a coesão social." "A criminalização pode ser expressa também pelo tratamento discriminatório da lei ou das políticas quando estas exigem de migrantes condições e comportamentos que não são exigidos dos nacionais ou vice-versa [...].
\end{abstract}

Segundo Long (2014), uma das maiores dificuldades acerca do acolhimento e da proteção dos refugiados reside na questão da colaboração dos Estados, e no convencimento de que esses indivíduos não seriam um fardo (burden) para a sociedade que os acolhe. Conforme ela, os cidadãos desses Estados "permanecem firmemente comprometidos com um sistema no qual" são eles os sujeitos que possuem o "direito de ter direitos" (LONG, 2014, p. 8), e não os migrantes, sejam eles refugiados ou não. Portanto, além das restrições fronteiriças na UE, as quais buscam dificultar a mobilidade dos imigrantes extracomunitários (CUNHA, 2014), utilizam-se de artifícios, por meio de discursos ou ações, que excluem os migrantes, até mesmo os refugiados, ainda que esses estejam em uma condição de vulnerabilidade.

Dessa forma, entende-se necessário que as políticas tomadas pelos países da UE que dificultam o acolhimento dos refugiados, como a própria securitização da migração, sejam repensadas e evitadas. Torna-se imprescindível, assim, desconstruir a percepção dos refugiados como uma ameaça existencial, tendo em vista especialmente a sua situação de vulnerabilidade, pois essa percepção pode contribuir para a falta de cooperação dos atores (Estados) em proteger esses indivíduos.

0 acolhimento dos refugiados na UE: medidas e soluções

O regime internacional para a proteção dos refugiados, criado por meio da Convenção de 1951 e do Protocolo de 1967, tem como principal objetivo assegurar a proteção desses migrantes forçados, pois eles são perseguidos e/ou sofrem abusos de direitos humanos em seus Estados de origem, e, por esse motivo, buscam refúgio em outros países. Dessa forma, a cooperação entre os Estados é uma etapa primordial para o acolhimento dos refugiados (BETTS, 2009). Atinente a isso, o Alto Comissariado das Nações Unidas para Refugiados (ACNUR) possui como função "dirigir e coordenar a ação internacional para proteger e ajudar as pessoas deslocadas em todo o mundo e encontrar soluções duradouras para elas" (ACNUR, 2017, s/p). No entanto, essa agência não consegue trabalhar de forma eficaz para garantir essa proteção sem a cooperação dos Estados (LOESCHER, 2014), tendo em vista que eles atuam nos regimes e nas instituições de acordo com seus interesses (BETTS, 2009).

Segundo Betts (2009), o regime dos refugiados foi criado porque se acreditava que a contribuição coletiva dos Estados poderia superar vários problemas gerados pelas migrações forçadas, como a própria insegurança dos Estados nos âmbitos econômico e social. Desse modo, para o autor, ao criarem um regime internacional para a proteção dos refugiados, os Estados não agiram de forma altruísta (BETTS, 2009), uma vez que o próprio conceito de regime conota a convergência de interesses entre os atores que participam de sua elaboração (KRASNER, 2012). Saliente-se, aqui, que, segundo Krasner (2012, p. 93), "os regimes são definidos como 
princípios, normas, regras e procedimentos de tomada de decisões de determinada área das relações internacionais em torno dos quais convergem as expectativas dos atores".

A garantia de proteção aos refugiados é uma questão de interesse tanto dos direitos humanos, devido às violações no que diz respeito a esses direitos, quanto da segurança internacional (BETTS, 2009, p. 1), pois ao deixarem seu país de origem, esses migrantes forçados podem ser vistos como uma ameaça em potencial para os outros Estados. A depender dos seus interesses, os Estados da UE podem lidar com migrações forçadas como momentos oportunos para preencher a demanda de mão-de-obra barata; mas também podem criar a percepção de que esses indivíduos são uma ameaça (PODDAR, 2016), colocando em risco a vida do próprio refugiado, quando ele não é acolhido devidamente. Portanto, torna-se imprescindível refletir sobre medidas que construam melhores formas de lidar com o dilema das migrações e com o acolhimento dos refugiados.

A solução para acabar com as migrações forçadas parece ser estritamente política, uma vez que envolve decisões locais onde ocorrem os conflitos que as provocam. No entanto, enquanto os Estados de origem não garantam os direitos necessários para evitar o deslocamento de pessoas, os Estados de acolhimento possuem a função essencial na proteção dos refugiados. No caso da União Europeia, a primeira política que poderia ser feita, poderia ser evitar a disseminação da percepção de que a migração representa uma ameaça existencial. Além disso, nesse caso, seria necessário fornecer informações corretas sobre as categorias dos migrantes, evitando discursos políticos contrários ao acolhimento dos refugiados.

Para que o acolhimento dos refugiados seja eficaz, como visto, é necessário que os Estados cooperem. Quando esses atores cooperam, espera-se que outros Estados também o façam, dando base para o chamado "burden sharing", que por sua vez visa o compartilhamento das responsabilidades entre os países do Sul e do Norte na proteção dos refugiados (GOTTWALD, 2014).

O burden sharing é feito de forma voluntária por parte dos países (GOTTWALD, 2014, p. 3), o que faz com que muitas vezes esses atores se eximam de suas obrigações enquanto "protetores" dos refugiados, e o burden-sharing pode não ser assegurado e nem eficaz (BETTS, 2009). Ademais, ao compreender que os Estados não contribuem altruisticamente para essa proteção, Betts (2009) afirma que convém utilizar um mecanismo que facilite a cooperação dos Estados, mecanismo esse chamado pelo autor de "cross-issue persuasion". Essa medida visa ligar a questão da proteção dos refugiados com um tema de interesse dos Estados. Para que isso seja concretizado, deve-se realizar um processo de convencimento, uma barganha, em que um ator A pode persuadir um ator B a acreditar que uma determinada área x é ligada a uma área y e assim o ator $\mathrm{B}$ contribui com o ator A (BETTS, 2009). Essa seria uma solução, de acordo com Betts (2009), para que os Estados cooperem mais com o regime de proteção para os refugiados. Assim, compreende-se que é preciso persuadir os Estados de que existe uma relação entre os seus interesses e a proteção desses indivíduos. 
O mecanismo de cross-issue persuasion proposto por Betts pode ser aplicado no caso dos Estados-membros da União Europeia, os quais têm como opção interligar os seus interesses à proteção dos refugiados (BETTS, 2009). Nesse sentido, em vez de se utilizarem das migrações como uma questão de segurança, prejudicando a proteção dos refugiados, os Estados deveriam colaborar com o acolhimento desses indivíduos.

Para além dessas questões sobre a política do acolhimento para os refugiados no local em que solicitam refúgio, considera-se importante atentar para outros pontos que envolvem a temática relacionada à proteção desses indivíduos, como sua integração local. Como exposto na segunda seção, a securitização da migração contribui para a exclusão dos refugiados nas sociedades de acolhimento, abrindo espaço para que nem mesmo os seus direitos básicos, como saúde e educação, sejam garantidos.

Segundo Pacífico (2010), os refugiados não deveriam ficar à mercê da política, tendo em vista que já sofreram abusos desde os seus países de origem e, ainda assim, sofrerem preconceito no local em que se encontram amparados. De acordo com essa autora, é necessário considerar, além da proteção física, a questão psicológica dos refugiados, uma vez que eles sentem as consequências da sua migração forçada, apresentando sintomas de traumas e frustrações e, mais, têm que lidar com uma nova sociedade, uma nova cultura, uma nova língua, enfim, um modo de organização de vida diferente (PACÍFICO, 2010).

Posto isso, a União Europeia poderia colaborar para um melhor acolhimento dos refugiados, buscando implantar políticas públicas para facilitar a situação desses indivíduos no local de acolhimento, levando os refugiados a terem acesso aos direitos básicos, como segurança, saúde, educação, cursos profissionalizantes para que possam qualificar-se e, consequentemente, conseguir emprego; além disso, devem ter acesso também a comunidades religiosas das quais desejam fazer parte (PACÍFICO, 2010). Assim, reverberar sobre as condições dos refugiados e de seu acolhimento na UE, e, ainda, sobre os mecanismos que facilitem a cooperação dos Estados para o seu acolhimento, como o cross-issue persuasion, pode ser uma forma de desconstruir, paulatinamente, a percepção de que os refugiados representam uma ameaça existencial.

Considerações finais

As políticas restritivas migratórias nos países-membros da União Europeia têm sido praticadas com maior frequência desde o fim da Guerra Fria, quando se notou um aumento do fluxo migratório em direção aos seus países-membros (LOESCHER, 2014). No decorrer do tempo, essas práticas restritivas se tornaram atos naturais por meio do discurso constantemente utilizado sobre a temática na UE (DIJCK, 2006). Utiliza-se, como argumento, que as políticas de contenção ao "grande fluxo" de migrantes em direção a Europa, considerados em situação "irregular", é uma forma de garantir a segurança dos Estados da "ameaça existencial", que são os próprios imigrantes (DIJCK, 2006). Tratar as migrações como ameaças em potencial e, assim, colocar a questão em uma agenda de segurança, significa securitizar o assunto. Dessa forma, a partir do processo 
de securitização, as migrações adquirem caráter emergencial, permitindo que se utilizem de políticas de urgência, como as de controle restritivo nas fronteiras europeias.

As duras ações realizadas dentro da lógica da securitização da migração na União Europeia, como as detenções, justificam-se pelos possíveis malefícios e problemas sociais que os imigrantes poderiam gerar, sendo esses associados à criminalidade e à insegurança, representando até mesmo potenciais terroristas (WERMUTH, 2014). Essa temática faz parte dos principais debates da UE, que têm considerado as migrações uma questão de segurança. Segundo Wermuth (2014, p. 192), na UE se acredita que "os imigrantes - principalmente os oriundos da África - estariam abusando dos sistemas de proteção social europeus". Com isso, os casos de xenofobia e de discriminação contra os migrantes se mantêm e se intensificam (LUSSI, 2015). Assim, o processo de securitização pode ser feito de formas diferentes, por meio do discurso ou da criminalização dos migrantes (IDEM). Ao tratar o imigrante como criminoso, as restrições impostas às migrações se intensificam e, além disso, o índice de detenções e vigilância aumenta, tendo como justificativa a ilegalidade da situação dos imigrantes (WERMUTH, 2014), ainda que dentre eles estejam incluídos os refugiados.

Uma vez que as migrações irregulares são vistas como crimes, os refugiados estão sujeitos ao abuso dos direitos que os deveriam proteger (LUSSI, 2015). Compreende-se, então, que as políticas restritivas migratórias, consequência da securitização da temática, criam barreiras ao acolhimento dos refugiados, como é o caso da Itália, onde esses migrantes forçados são considerados migrantes ilegais e são mantidos em celas de detenção (GARCIA, 2014). Garcia (2014) entende que, nessas circunstâncias, as normas internacionais para a proteção dos refugiados são desrespeitadas, tendo em vista que se pratica expulsões coletivas desses indivíduos, os quais são mantidos em centros de detenção, chamados "centros de acolhimento", apenas por não carregarem consigo documentos ou vistos que comprovem a sua "legalidade". Segundo essa autora, alguns centros de detenção dos migrantes na Itália, por exemplo, encontram-se em situação clandestina, em que todos os migrantes, sem distinção de categorias, são mantidos em um mesmo espaço (GARCIA, 2014). De acordo com Garcia (2014), todos os migrantes são mantidos no mesmo local, estando presentes mulheres grávidas, crianças, homens, criminosos e refugiados.

Em períodos de economia instável, ainda é mais fácil utilizar-se do argumento de que o migrante representa uma ameaça ao Estado, sendo associado à intensificação da instabilidade e de aumento de despesas públicas (PODDAR, 2016). É importante lembrar que uma vez que o Estado de acolhimento adquire a responsabilidade de proteger o refugiado, primeiro ele deve fornecer refúgio e, depois, prover serviços básicos, como segurança, saúde e educação. É o básico a ser garantido. Em vez de prestar essa assistência, observou-se que a política europeia tende a esquivar-se de suas responsabilidades, esquecendo-se da segurança dos próprios indivíduos (refugiados) em nome da segurança estatal. Assim, interpreta-se que considerar os refugiados uma ameaça à sociedade pode 
ser uma forma oportuna dos países da União Europeia não serem responsabilizados pelos indivíduos que necessitam de assistência.

Portanto, torna-se imprescindível que o discurso securitizador da migração e as atuações restritivas contra os imigrantes na União Europeia sejam repensados, especialmente atentando para o fato da necessidade de que os refugiados sejam acolhidos pelos Estados desse bloco. Os autores deste artigo creem ser necessário que, em vez de barreiras, esses países construam pontes a fim de melhorar essa proteção. $\mathrm{O}$ regime que coordena as questões relativas à proteção dos refugiados tem justamente como uma das principais finalidades assistir a essa política, no entanto, não consegue trabalhar de forma eficaz sem a cooperação dos Estados (BETTS, 2009). Dessa forma, a proposta de Betts (2009), qual seja, o cross-issue persuasion, é de suma importância, enquanto mecanismo de contribuição para um melhor acolhimento dos refugiados, auxiliando-os a superar seus traumas e a construir uma nova vida.

Referências

ACNUR. Convenção Relativa ao Estatuto dos Refugiados. Nova Iorque: AGNU, 1951. Disponível em: <http://www.acnur.org/t3/fileadmin/Documentos/portugues/BDL/Convencao_ relativa_ao_Estatuto_dos_Refugiados.pdf $>$. Acesso em: 3 nov. 2017.

ACNUR. O Acnur. 2017. Disponível em: <http://www.acnur.org/portugues/o-acnur/>. Acesso em: 10 dez. 2017.

ALVES, Laís Azeredo. O processo de securitização e despolitização do imigrante: a política migratória italiana nos anos 1990 - 2000. 2015. 121 f. Dissertação (Mestrado em Relações Internacionais) - Programa San Tiago Dantas de Pós-Graduação em Relações Internacionais, UNESP/UNICAMP/PUC-SP, 2015.

AMNESTY INTERNATIONAL. The State of The World's Human Rights. London, 2018. Disponível em: <https://www.amnesty.org/download/Documents/POL1067002018ENGLISH. PDF>. Acesso em: 12 fev. 2019.

ASSOCIAZONE PER GLI STUDI GIURIDICI SULL'IMMIGRAZIONE (ASGI). Integrazione dei rifugiati a rischio senza accesso alla residenza. Bologna, 23 maio 2014. Disponível em: $<$ https://www.asgi.it/notizie/integrazione-dei-rifugiati-a-rischio-senza-accesso-alla-residenza/>. Acesso em: 14 fev. 2019.

ASSOCIAZONE PER GLI STUDI GIURIDICI SULL'IMMIGRAZIONE (ASGI). Short overview of the Italian reception system. Bologna, 2019. Disponível em: $<$ https://www.asylumineurope.org/reports/country/italy/reception-conditions/short-overview-italian-reception-system $>$. Acesso em: 11 fev. 2019.

BARNETT, Laura. Global Governance and the evolution of the International Refugee Regime. International Journal of Refugee Law, Oxford University Press, v. 14, n. 2/3, p. 238-262, 2002. Disponível em: <http://archives.cerium.ca/IMG/pdf/Barnett.pdf>. Acesso em: 8 jan. 2018.

BETTS, Alexander. Protection by Persuasion: International Cooperation in the Refugee Regime. Ithaca and London: Cornell University Press, 2009.

BUZAN, Barry; WÆVER, Ole; WILDE, Jaap De. Security: a new framework for analysis. London: Lynne Rienner Publishers, 1998.

CASTLES, Stephen. As migrações internacionais no limiar do século XXI: Questões e tendências globais. In: CASTLES S. Globalização, transnacionalismo e novos fluxos migratórios. Lisboa: Fim de Século, cap. 1, 2005.

COSKUN, Bezen Balamir. An evaluation of the Eu's Migration Policies after Arab Spring. Journal of Culture Studies, v. 2, n. 1, p. 42-59, 2015. Disponível em: <https://www.researchgate. net/publication/279194133_An_Evaluation_of_the_Eu's_Migration_Policies_after_Arab_ Spring $>$. Acesso em: 15 nov. 2017.

CUNHA, Higor Hebert França da. Quem é bem-vindo? A securitização da migração e o papel da União Europeia e da Itália. Revista Ambivalência, v. 2, n. 4. p.189-213, 2014. Disponível em: <https://seer.ufs.br/index.php/Ambivalencias/article/view/3604/3083>. Acesso em: 17 nov. 2017. 
DE GENOVA, Nicholas. (Ed.) The Borders of 'Europe': Autonomy of Migration, Tactics of Bordering. Durham: Duke University Press, 2017.

DIJCK, Dominique Van. Is the EU policy on illegal immigration securitized? Paper to presented at he 3rd Pan-European Conference on EU Politics, Istanbul, 21-23 September 2006. Disponível em: <http://www.jhubc.it/ecpr-istanbul/virtualpaperroom/054.pdf >. Acesso em: 12 nov. 2017.

EUROPEAN BORDER AND COAST GUARD AGENCY (Frontex). Mission and tasks. Warsaw, 2017. Disponível em: <http://frontex.europa.eu/about-frontex/mission-and-tasks/>. Acesso em: 10 dez. 2017

FARGUES, Philippe; FANDRICH, Christine. Migration after the Arab Spring. MPC - Migration PoliCy Centre, $N^{\circ}$ 9, Robert Schuman Centre for Advanced Studies, San Domenico di Fiesole (FI): European University Institute, 2012

FERREIRA, Susana de Sousa. Migrations and the Arab Spring - a new security nexus? Human Security Perspectives, v. 10, issue 4, p. 62-90, 2014. Disponível em: $<$ https://run.unl.pt/handle/10362/28969>. Acesso em: 13 nov. 2017.

GARCIA, Fernanda Di Flora. A exceção é a regra: os centros de detenção para imigrantes na Itália. Revista Interdisciplinar de Mobilidade Humana, Brasília, n. 43, p. 235-250, 2014. Disponível em: <http://www.scielo.br/pdf/remhu/v22n43/v22n43a15.pdf>. Acesso em: 2 dez. 2017.

GATTINARA, Pietro Castelli. The 'refugee crisis' in Italy as a crisis of legitimacy. Contemporary Italian politics, v. 9, n. 3, p. 318-331, 2017.

GIULIANI, Marta. A situação da imigração na Itália a partir das contribuições do Dossiê Estatístico sobre Imigração Caritas/Migrantes. Revista Interdisciplinar de Mobilidade Humana, Brasília, n. 39, p. 279-292, 2012. Disponível em: <http://www.scielo.br/pdf/remhu/v20n39/ v20n39a15.pdf>. Acesso em: 5 dez. 2017.

GLOBAL DETENTION PROJECT. Italy Immigration Detention Profile. Geneva, 2018. Disponível em: <https://www.globaldetentionproject.org/immigration-detention-in-italy-2>. Acesso em: 12 fev. 2019.

GOTTWALD, Martin. Burden. Sharing and refugee Protection. In: FIDDIAN-QASMIYEH, Elena et al (Ed.). The Oxford Handbook of Refugee and Forced Migration Studies, Oxford: Oxford University Press, p. 525-537, 2014.

HARRELL-BOND, Barbara; VOUTIRA, Efitihia. Search of 'Invisible' Actors: Barriers to Access in Refugee Research. Journal of Refugee Studies, Oxford, v. 20, n. 2, p. 281-298, 2007.

HUYSMANS, Jef. The European Union and the Securitization of Migration. Journal of Common Market Studies, v. 38, n. 5, p.751-777, 2000.

IOV, Claudia Anamaria; BOGDAN, Maria Claudia. Securitization of migration in the European Union - between discourse and practical action. Research and science today, v. 13, n. 1, 2017. Disponível em: <www.rstjournal.com>. Acesso em: 26 out. 2017.

JOFFÉ, George. A Primavera Árabe no Norte da África: Origens e Perspectivas de futuro. Relações Internacionais, Lisboa, n. 30, p. 85-116, 2011. Disponível em: <http://www.scielo.mec.pt/ scielo.php?script=sci_arttext\&pid=S1645-91992011000200006>. Acesso em: 13 nov. 2017.

KASPAREK, Bernd. Complementing Schengen: The Dublin System and the European Border and Migration Regime. In.: BAUDER, Harald; MATHEIS, Christian. Migration Policy and Practice: Interventions and Solutions. New York City (USA): Palgrave Macmillan US, p. 59-76, 2016.

KRASNER, Stephen D. Causas estruturais e consequências dos regimes internacionais: regimes como variáveis intervenientes. Revista de Sociologia e Política, v. 20, n. 42, p. 93-110, 2012.

LOESCHER, Gil. UNHCR and Forced Migration. In: FIDDIAN-QASMIYEH, Elena et al (Ed.). The Oxford Handbook of Refugee and Forced Migration Studies. Oxford: Oxford University Press, p. 215-226, 2014.

LONG, Katy. Rethinking 'Durable' Solutions. In: FIDDIAN-QASMIYEH, Elena et al (Ed.). The Oxford Handbook of Refugee and Forced Migration Studies. Oxford: Oxford University Press, p. 475-487, 2014

LUSSI, Carmem. Políticas públicas e desigualdades na migração e refúgio. Psicologia USP, v. 26, n. 2, p. 136-144, 2015. Disponível em: <http://www.scielo.br/pdf/pusp/v26n2/0103-6564pusp-26-02-00136.pdf>. Acesso em: 25 nov. 2017.

MARINUCCI, Roberto. Proteger os migrantes forçados ou proteger-se deles? Revista Interdisciplinar de Mobilidade Humana, Brasília, ano XXII, n. 43, pp. 7-9, 2014. Disponível em: $<$ http://www.scielo.br/pdf/remhu/v22n43/v22n43a01.pdf >. Acesso em: 9 jan. 2018. 
MARTINO, Alberto di et al. The criminalization of irregular immigration: law and practice in Italy. Pisa: Pisa University Press, 2012. Disponível em: <http://irma.eliamep.gr/wp-content/ uploads/2013/05/the-criminalization-of-irregular-immigration.pdf >. Acesso em: 13 fev. 2019.

MEZZADRA, S.; NEILSON, B. Border as method or the multiplication of labor. European Institute for Progressive Cultural Policies, 2008. Disponível em: $<$ http://eipcp.net/transversal/0608/mezzadraneilson/en>. Acesso em: 22 jan. 2019.

NYERS, Peter. Abject Cosmopolitanism: the politics of protection in the anti-deportation movement. Third World Quarterly, v. 24, n. 6, p. 1069-1093, 2003.

PACÍfICO, Andrea Pacheco. O Capital Social dos Refugiados. Maceió: Edufal. 2010.

PAOLETTI, Emanuela. The Arab Spring and the Italian Response to Migration in 2011: Beyond the Emergency. Comparative migration Studies, v. 2, n. 2, p. 127-150, 2014. Disponível em: <https://link.springer.com/article/10.5117/CMS2014.2.PAOL>. Acesso em: 26 nov. 2017.

PAOLETTI, Emanuela. Power Relations and International Migration: The Case of Italy and Libya. Political studies, Vol: 59, 2011, pp. 269-289.

PEREIRA, Joaquim André Gomes. Da crise de refugiados na Europa: Uma ameaça à segurança? 2016. 215 f. Dissertação (Mestrado integrado em Ciências Policiais) - XXVIII Curso de Formação de Oficiais de Polícia, Instituto Superior de Ciências Policiais e Segurança Interna, 2016. Disponível em: <https://comum.rcaap.pt/handle/10400.26/15560>. Acesso em: 10 dez. 2017.

PODDAR, Shubham, European Migrant Crisis: Financial Burden or Economic Opportunity? Social Impact Research Experience (SIRE), n. 43, 2016. Disponível em: <http://repository. upenn.edu/sire/43>. Acesso em: 29 nov. 2017.

ROCHA, Rossana Reis; MOREIRA, Julia Bertino. Regime Internacional para refugiados: mudanças e desafios. Revista de Sociologia Política, Curitiba, v. 18, n. 37, p. 17-30, 2010. Disponível em: <http://www.scielo.br/pdf/rsocp/v18n37/03.pdf>. Acesso em: 26 nov. 2017.

SARAIVA, María Francisca Alves Ramos de Gil. A securitização da crise dos refugiados na Europa. Implicações para o complexo de regimes sobre migrações internacionais. Revista de Estudios en Seguridad Internacional, v. 3, n. 1, p. 43-60, 2017. Disponível em: <http://dx.doi. org/10.18847/1.5.3 >. Acesso em: 25 out. 2017.

SCHENGEN VISA INFO. Schengen Area Countries List. 2017. Disponível em: <https://www. schengenvisainfo.com/schengen-visa-countries-list/ >. Acesso em: 26 out. 2017.

SMITH, Steve. Introduction: Diversity and Disciplinarity in International Relations Theory. In.: DUNNE, Tim; KURKI, Milja; SMITH, Steve. International Relations Theory: Discipline and Diversity. Oxford: Oxford University Press, p. 1-12, 2013.

UNIÃO EUROPEIA. Sistema Europeu Comum de Asilo (SECA). Luxemburgo: Serviço das Publicações da União Europeia, 2014. Disponível em: <https://ec.europa.eu/home-affairs/sites/ homeaffairs/files/e-library/docs/ceas-fact-sheets/ceas_factsheet_pt.pdf $>$. Acesso em: 26 ago. 2018.

VELASCO, Suzana de Souza Lima. A securitização da imigração na União Europeia: legislação e práticas de regulação do excesso de mobilidade. In: VELASCO, S. de S. L. Imigração na União Europeia: uma leitura crítica a partir do nexo entre securitização, cidadania e identidade transnacional. Campina Grande: EDUEPB, pp. 65-107, 2014.

VOUTIRA, Eftihia; DONÁ, Giorgia. Refugee Research Methodologies: Consolidation and Transformation of a Field. Journal of Refugee Studies. v. 20, n. 2, Oxford: Oxford University Press, p. 163-171, 2007.

WERMUT, Maiquel Ângelo Dezordi. Direito penal, migrações e mixofobia na União Europeia. Revista científica internacional, v. 1, n. 31, p.174-267, 2014. Disponível em: <http://www.interscienceplace.org/isp/index.php/isp/article/view/305>. Acesso em: 25 nov. 2017. 